\title{
A ring-closing metathesis approach to a synthesis of the $B$ ring of eleutherobin
}

\author{
Krishna P. Kaliappan* and Nirmal Kumar \\ Department of Chemistry, Indian Institute of Technology-Bombay, Powai, 400076 Mumbai, India
}

\begin{abstract}
A short and efficient RCM route is reported for the construction of the key nine-membered B ring of eleutherobin starting from the readily available 1,2,5,6-diisopropylidene-D-glucose.
\end{abstract}

The success of $\operatorname{taxol}^{\circledR}$ (paclitaxel) against breast and ovarian cancer has elicited a worldwide search for better sources and improved analogues of this drug which might operate through similar modes of action. ${ }^{1}$ This led to the discovery of the new natural products discodermolide, epothilones and eleutherobin which displaying a paclitaxel-like mechanism of action. Among them, the latest discovery, eleutherobin $\mathbf{1}^{2}$ was isolated from a marine soft-coral found in the Indian Ocean and found to be closely related to sarcodictyins $\mathbf{2}, \mathbf{3}^{3}$ and valdivone $4 .^{4}$ Eleutherobin has been shown to possess potent cytotoxicity with an $\mathrm{IC}_{50}$ of $10.7 \mathrm{nM}$ which is comparable to taxol. As eleutherobin was only available in scarce amounts from natural sources, chemical syntheses have become more imperative to study its biological properties further. This prompted synthetic chemists to develop new strategies ${ }^{5}$ to synthesize eleutherobin and their sustained efforts have culminated in two total syntheses. ${ }^{6,7}$ However, convenient access to the fully functionalized nine-membered B ring remains a challenge in the synthesis of eleutherobin.

As a part of our program directed towards the development of simple and efficient routes to the syntheses of tubulin binding anticancer agents, we became interested in the synthesis of eleutherobin and its congeners. A strategy for the synthesis of eleutherobin was designed based on the retrosynthetic analysis shown in Scheme 1. We envisaged that a ring-closing metathesis (RCM) reaction ${ }^{8}$ would be an ideal key reaction to construct these natural product skeletons. Eleutherobin possesses

Keywords: eleutherobin; Grubbs' catalyst; RCM; chemical synthesis; nine-membered ring.
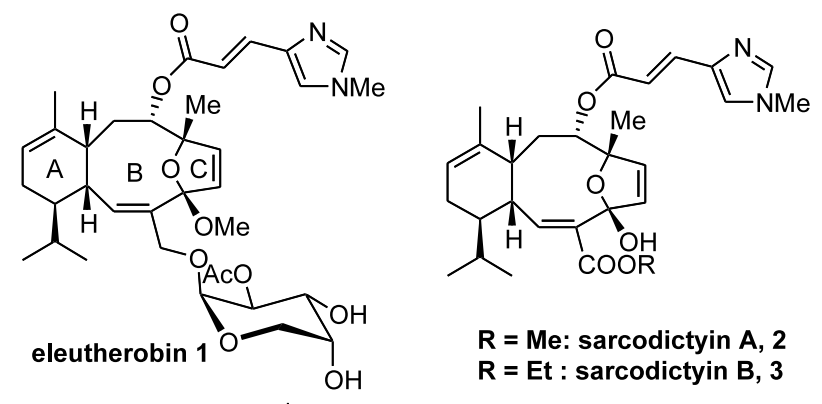

$\mathbf{R}=$ Me: sarcodictyin $A, 2$ $R=E t:$ sarcodictyin $B, 3$

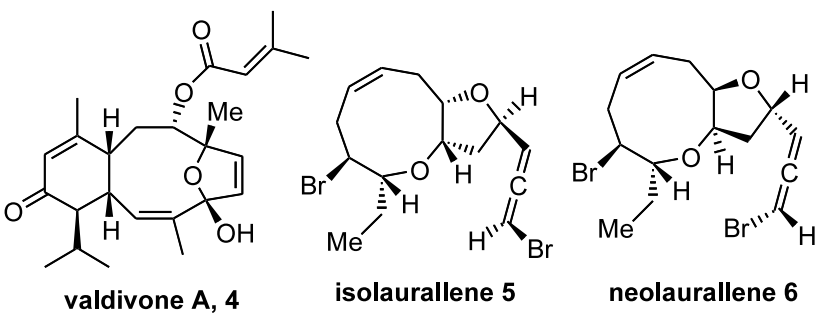

three double bonds, however to be formed as a result of an RCM reaction, only disconnection of the $\mathrm{B}$ ring double bond will simplify the target molecule leading to precursor $\mathbf{C}$ which then can be further disconnected to the bicyclic enone 7 and the epoxide 8 . It is clear that the success of our synthetic route to eleutherobin depends heavily on the construction of the B ring with the strategically placed double bond. So, a model study was carried out to synthesize the highly oxygenated nine-membered ether ring $^{9}$ starting from the readily available 1,2,5,6-diisopropylidene-D-glucose and herein we report our initial results.

Our synthesis, as depicted in Scheme 2, starts with the classical etherification of the secondary alcohol 9 to afford 10. Under mild acidic conditions, the more exposed 5,6-O-isopropylidene group was selectively 

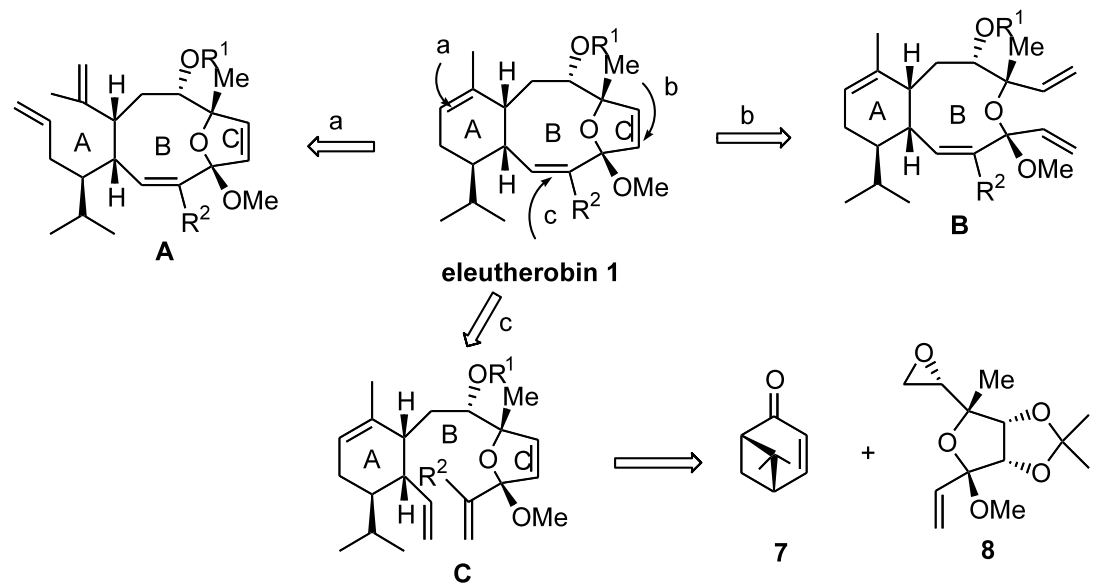

Scheme 1.
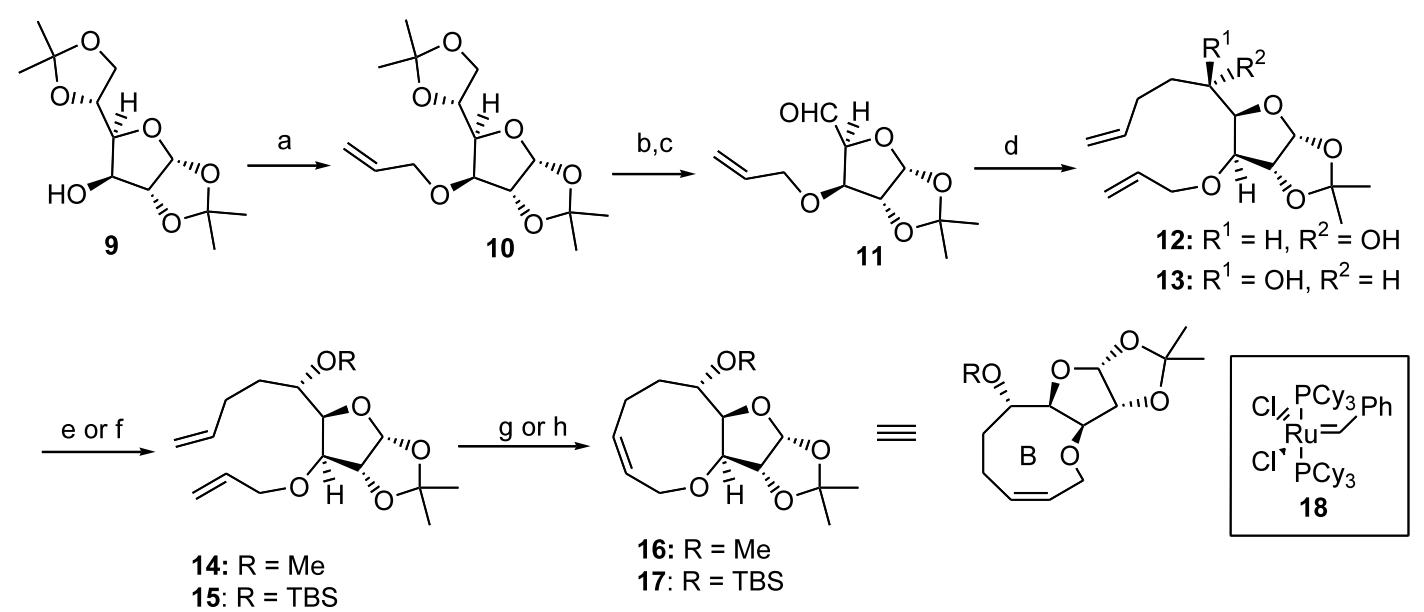

Scheme 2. Reagents and conditions: (a) NaH, allylbromide, THF, TBAI (cat.), rt, $2 \mathrm{~h}, 93 \%$; (b) $60 \%$ aq. $\mathrm{AcOH}, \mathrm{H}_{2} \mathrm{O}, 12 \mathrm{~h}, 90 \%$; (c) silica gel supp. $\mathrm{NaIO}_{4}, \mathrm{CH}_{2} \mathrm{Cl}_{2}, 30 \mathrm{~min}, 86 \%$; (d) 4-bromo-1-butene, $\mathrm{Mg}$, THF, $0^{\circ} \mathrm{C}$ to rt, $12 \mathrm{~h}, 83 \%$; (e) $\mathrm{NaH}, \mathrm{MeI}, 0^{\circ} \mathrm{C}$ to rt, $2 \mathrm{~h}, 77 \%$; (f) TBSCl, imid., DMF, $0^{\circ} \mathrm{C}$ to rt, $10 \mathrm{~h}, 84 \%$; (g) 18 (10 mol $\left.\%\right), \mathrm{CH}_{2} \mathrm{Cl}_{2}, 40^{\circ} \mathrm{C}, 2 \mathrm{~h},(33 \%$ for $\mathrm{R}=\mathrm{Me}, 30 \%$ for $\mathrm{R}=\mathrm{TBS})$; (h) $18(10 \mathrm{~mol} \%)$, $\mathrm{Ti}(\mathrm{O} i \mathrm{Pr})_{4}(7.5 \mathrm{~mol} \%), \mathrm{CH}_{2} \mathrm{Cl}_{2}, 40^{\circ} \mathrm{C}(63 \%$ for $\mathrm{R}=\mathrm{Me}, 83 \%$ for $\mathrm{R}=\mathrm{TBS})$.

deprotected to give a diol which was subsequently cleaved by treating with silica gel supported $\mathrm{NaIO}_{4}{ }^{10}$ to afford 11. Addition of the Grignard reagent, derived from 4-bromo-1-butene and magnesium, to the aldehyde $\mathbf{1 1}$ afforded two diastereomeric products $\mathbf{1 2}$ and $\mathbf{1 3}$ as a readily separable mixture in $3: 2$ ratio $^{11}$ and good chemical yield. Subsequent protection of the major alcohol 12 as its methyl ether set the stage for the key RCM reaction. Unfortunately, when the RCM was carried out with Grubbs catalyst 18 under high dilution conditions ( 0.003 M solution with $10 \%$ catalyst), only $33 \%$ of the desired cyclized product 16 was obtained, the remainder being unreacted starting material and presumably some crossmetathesis product. The observation of a similar result with the TBS ether 15, prepared from 12, suggested that the low yield could be attributed to coordination of the metal centre with the oxygen of the furanose ring. ${ }^{12}$ In order to destabilize this chelate structure, the RCM reaction of the dienes $\mathbf{1 4}$ and $\mathbf{1 5}$ was carried out with a catalytic amount of $\mathbf{1 8}$ in the presence of a sub-stoichiometric amount of $\mathrm{Ti}(\mathrm{O} i \mathrm{Pr})_{4}{ }^{13}$ and this modified protocol successfully led to the formation of the desired RCM products 16 and 17 , respectively in high yields. ${ }^{14}$

In summary, a seven-step synthesis of a highly oxygenated model of the key nine-membered $\mathrm{B}$ ring of eleutherobin was successfully achieved from commercially available D-glucose. Interestingly, the RCM products 16 and 17 possess all the structural features of the marine natural products isolaurallene $4^{15}$ and neolaurallene 5. ${ }^{16}$ We are currently examining the extension of this methodology, in our laboratory, to synthesize these natural products, in addition to eleutherobin and its congeners. 


\section{Acknowledgements}

The International Foundation for Science, Sweden, is sincerely acknowledged for the financial support. One of us (N.K.) thanks the CSIR, New Delhi, for a fellowship. We also thank Professor K. K. Balasubramanian, Shasun Chemicals for recording the ${ }^{1} \mathrm{H}$ and ${ }^{13} \mathrm{C} \mathrm{NMR}$ spectra of some samples. We also thank Professor $\mathrm{M}$. C. Pirrung, Duke University for a generous gift of some chemicals.

\section{References}

1. For a recent review on taxol, see: Kingston, D. G. I. Chem. Commun. 2001, 867.

2. (a) Fenical, W.-H.; Hensen, P. R.; Lindel, T. US Patent No. 5,473,057, Dec. 5, 1995; (b) Lindel, T.; Jensen, P. R.; Fenical, W.; Long, B. H.; Casazza, A. M.; Carboni, J.; Fairchild, C. R. J. Am. Chem. Soc. 1997, 119, 8744.

3. (a) D'Ambrosio, M.; Guerriero, A.; Pietra, F. Helv. Chim. Acta 1987, 70, 2019; (b) D'Ambrosio, M.; Guerriero, A.; Pietra, F. Helv. Chim. Acta 1988, 71, 964.

4. Lin, Y.; Bewley, C. A.; Faulkner, D. J. Tetrahedron 1993, 49, 7977.

5. (a) Rainier, J. D.; Xu, Q. Org. Lett. 1999, 1, 27; (b) Rainier, J. D.; Xu, Q. Org. Lett. 1999, 1, 1161; (c) Ceccarelli, S.; Piarulli, U.; Gennari, C. Tetrahedron Lett. 1999, 40, 153; (d) Baron, A.; Caprio, V.; Mann, J. Tetrahedron Lett. 1999, 40, 9321; (e) Kim, P.; Nantz, M. H.; Kurth, M. J.; Olmstead, M. M. Org. Lett. 2000, 2, 1831; (f) Carter, R.; Hodgetts, K.; McKenna, J.; Magnus, P.; Wren, S. Tetrahedron 2000, 56, 4367; (g) Ceccarelli, S.; Piarulli, U.; Gennari, C. J. Org. Chem. 2000, 65, 6254; (h) By, K.; Kelly, P. A.; Kurth, M. J.; Olmstead, M. M.; Nantz, M. H. Tetrahedron 2001, 57, 1183; (i) Ceccarelli, S.; Piarulli, U.; Telser, J.; Gennari, C. Tetrahedron Lett. 2001, 42, 7421; (j) Ceccarelli, S.; Piarulli, U.; Gennari, C. Tetrahedron 2001, 57, 8531; (k) Xu, Q.; Weeresakare, M.; Rainier, J. D. Tetrahedron 2001, 57, 8029; (1) Telser, J.; Beumer, R.; Bell, A. A.; Ceccarelli, S. M.; Monti, D.; Gennari, C. Tetrahedron Lett. 2001, 42, 9187; (m) Sandoval, C.; Redero, E.; Timoneda, M. M. A.; Bermejo, F. A. Tetrahedron Lett. 2002, 43, 6521.

6. Nicolaou, K. C.; van Delft, F.; Ohshima, T.; Vourloumis, D.; Xu, J. Y.; Hosokawa, S.; Pfefferkorn, J.; Kim, S. Angew. Chem., Int. Ed. Engl. 1997, 36, 2520.

7. Chen, X.-T.; Bhattacharya, S. K.; Zhou, B.; Gutteridge, C. E.; Pettus, T. R. R.; Danishefsky, S. J. J. Am. Chem. Soc. 1999, 121, 6563.
8. For recent reviews on the RCM reaction, see: (a) Trnka, T. M.; Grubbs, R. H. Acc. Chem. Res. 2001, 34, 18-29; (b) Furstner, A. Angew. Chem., Int. Ed. 2000, 39, 3012; (c) Roy, R.; Das, S. Chem. Commun. 2000, 519; (d) Phillips, A. J.; Abell, A. D. Aldrichim. Acta 1999, 32, 75; (e) Wright, D. L. Curr. Org. Chem. 1999, 3, 211; (f) Alkene Metathesis in Organic Synthesis; Fürstner, A., Ed.; Springer: Berlin, 1998; (g) Armstrong, S. K. J. Chem. Soc., Perkin Trans. 1 1998, 371; (h) Grubbs, R. H.; Chang, S. Tetrahedron 1998, 54, 4413; (i) Schuster, M.; Blechert, S. Angew. Chem., Int. Ed. Engl. 1997, 36, 2037.

9. (a) Crimmins, M. T.; Choy, A. L. J. Am. Chem. Soc. 1999, 121, 5653; (b) Crimmins, M. T.; Emmitte, K. A.; Choy, A. L. Tetrahedron 2002, 58, 1817; (c) Rodriguez, J. R.; Castedo, L.; Mascarenas, J. L. Chem. Eur. J. 2002, 8, 2923.

10. Zhong, Y.-L.; Shing, T. K. M. J. Org. Chem. 1997, 62, 2622.

11. (a) Inch, T. D. Carbohydr. Res. 1967, 5, 45; (b) Wolfrom, M. L.; Hanessian, S. J. Org. Chem. 1962, 27, 1800.

12. Fürstner, A.; Langemann, K. Synthesis 1997, 792.

13. Fürstner, A.; Kindler, N. J. Am. Chem. Soc. 1997, 119, 9130.

14. All compounds reported here were duly characterized. Selected data: Compound 16: $R_{\mathrm{f}}=0.4$ [silica gel, ethyl acetate:hexane (4:1)], $[\alpha]_{\mathrm{D}}-63.9\left(c 1.0 \mathrm{CHCl}_{3}\right)$; IR: (neat, $\mathrm{cm}^{-1}$ ): 2940, 1657, 1466; ${ }^{1} \mathrm{H}$ NMR (300 MHz, $\left.\mathrm{CDCl}_{3}\right): \delta$ $5.89(\mathrm{~d}, J=3.8 \mathrm{~Hz}, 1 \mathrm{H}), 5.83(\mathrm{q}, J=9.2 \mathrm{~Hz}, 1 \mathrm{H}), 5.48(\mathrm{dt}$, $J=9.4,4.2 \mathrm{~Hz}, 1 \mathrm{H}), 4.43(\mathrm{~d}, J=3.8 \mathrm{~Hz}, 1 \mathrm{H}), 4.31(\mathrm{dd}$, $J=14.1,3.8 \mathrm{~Hz}, 1 \mathrm{H}), 4.06$ (d, $J=3.1 \mathrm{~Hz}, 1 \mathrm{H}), 4.01-3.51$ $(\mathrm{m}, 2 \mathrm{H}), 3.37(\mathrm{~s}, 3 \mathrm{H}), 3.37-3.32(\mathrm{~m}, 1 \mathrm{H}), 2.34-2.13(\mathrm{~m}$, $2 \mathrm{H}), 1.94-1.83(\mathrm{~m}, 1 \mathrm{H}), 1.41(\mathrm{~s}, 3 \mathrm{H}), 1.40-1.31(\mathrm{~m}, 1 \mathrm{H})$, $1.25(\mathrm{~s}, 3 \mathrm{H}) ;{ }^{13} \mathrm{C} \mathrm{NMR}\left(75 \mathrm{MHz}, \mathrm{CDCl}_{3}\right): \delta 135.6,125.6$, $111.5,104.8,85.3,83.4,82.5,80.5,65.9,57.5,27.9,26.8$, 26.4, 26.0. Compound 17: $R_{\mathrm{f}}=0.8$ [silica gel, ethyl acetate:hexane $\left.(4: 1)],[\alpha]_{\mathrm{D}}-39.9(c) 1.0 \mathrm{CHCl}_{3}\right)$; IR: (neat, $\left.\mathrm{cm}^{-1}\right)$ : 2947, 1650, 1255, 1091; ${ }^{1} \mathrm{H}$ NMR (300 MHz, $\left.\mathrm{CDCl}_{3}\right): \delta 5.9(\mathrm{~d}, J=3.7 \mathrm{~Hz}, 1 \mathrm{H}), 5.84(\mathrm{q}, J=9.1 \mathrm{~Hz}$, $1 \mathrm{H}), 5.52(\mathrm{dt}, J=10.2,5.1 \mathrm{~Hz}, 1 \mathrm{H}), 4.47(\mathrm{~d}, J=3.7 \mathrm{~Hz}$, $1 \mathrm{H}), 4.35(\mathrm{dd}, J=14.2,3.7 \mathrm{~Hz}, 1 \mathrm{H}), 4.08(\mathrm{~d}, J=2.9 \mathrm{~Hz}$, 1H), 3.96-3.82 (m, 3H), 2.39-2.14 (m, 2H), 1.91-1.51 (m, 2H), 1.47 (s, 3H), 1.30 (s, 3H), 0.88 (s, 9H), 0.09 (s, 3H), $0.08(\mathrm{~s}, 3 \mathrm{H}) ;{ }^{13} \mathrm{C} \mathrm{NMR}\left(75 \mathrm{MHz}, \mathrm{CDCl}_{3}\right): \delta 135.9,125.7$, 111.3, 104.6, 86.4, 84.1, 81.1, 73.8, 66.2, 33.2, 29.8, 26.9, $26.5,26.0,18.4,-4.3,-4.8$.

15. Kurata, K.; Furusaki, A.; Suehiro, K.; Katayama, C.; Suzuki, T. Chem. Lett. 1982, 1031.

16. Notaro, G.; Piccialli, V.; Sica, D.; Mayol, L.; Giordano, F. J. Nat. Prod. 1992, 55, 626. 